\title{
Vocal cord palsy after vincristine treatment in a child and the inefficacy of glutamic acid in the prevention of relapse: a case report
}

\author{
Piero Farruggia ${ }^{*}$, Serena Tropia ${ }^{1}$ Sonia Cannella ${ }^{1}$, Giuseppa Bruno ${ }^{1}$, Gaspare Oddo ${ }^{2}$ and Paolo D'Angelo ${ }^{1}$
}

\begin{abstract}
Introduction: Vincristine is an antineoplastic drug with a well known efficacy for the treatment of acute lymphoblastic leukemia and many solid tumors. No more than 20 pediatric patients with vincristine-induced vocal cord palsy have been reported, and to the best of our knowledge this is the first case where glutamic acid was administered with the aim of preventing a relapse of laryngeal dysfunction.

Case presentation: The larynx paralysis presented with hoarseness and stridor in a Caucasian 18-month-old girl and spontaneously resolved in about a month. In order to administer a subsequent full dose of vincristine, our patient received oral glutamic acid whose efficacy against vincristine neurological side effects has been previously reported.

Conclusions: Since in our patient the amino acid proved to be ineffective in the prevention of laryngeal paralysis relapse, we suggest that a dose reduction of vincristine should be preferred by oncologists as an initial approach after a case of drug-induced vocal cord palsy.
\end{abstract}

Keywords: Glutamic acid, Neuropathy, Vincristine, Vocal cord palsy

\section{Introduction}

Vinca alkaloids have a proven role in the treatment of hematological neoplasms. The basis of their action as mitotic inhibitors is binding to microtubule proteins, but they may cause axonal degeneration. In some cases, it is likely a role in the onset of neurotoxicity can be related to pre-existing liver dysfunction or concomitant use of drugs such as itraconazole, phenytoin, isoniazid, erythromycin, azoles or allopurinol. Rarely, vincristine (VCR) can produce vocal cord palsy (VCP) as a consequence of peripheral neurotoxicity involving cranial nerves, a potentially life-threatening event.

\section{Case presentation}

A Caucasian 18-month-old girl, born to an Italian family and raised in Italy, with a high-risk acute lymphoblastic leukemia (ALL) was being treated according to the AIEOP-

\footnotetext{
*Correspondence: farruggia.oep@ospedalecivicopa.org; pfarruggia@libero.it 'Oncology Department, Pediatric Hematology and Oncology Unit, A.R.N.A.S. Ospedali Civico, Di Cristina e Benfratelli, Piazza N. Leotta 4, Palermo 90127, Italy

Full list of author information is available at the end of the article
}

BFM ALL 2000 protocol. After the third dose of VCR $\left(1.5 \mathrm{mg} / \mathrm{m}^{2}\right)$ she developed isolated hoarseness, but stridor appeared soon after the fourth dose of VCR (last dose of induction phase). A flexible fiber-optic endoscope study showed a bilateral VCP (Figure 1). Electromyography revealed a predominantly axonal motor neuropathy involving above the lower extremities. A nerve conduction study of the larynx was not performed because the association of VCR administration with significant respiratory symptoms and immobility of the vocal folds, clearly shown by the fiber-optic endoscope, allowed us to make a definite diagnosis. No side effects of VCR other than VCP were found. Her stridor started to improve within the first seven days and both stridor and hoarseness completely resolved 28 days after the onset of palsy: a repeat laryngoscopy study showed normal vocal cord mobility.

Following two consolidation blocks it was decided to administer VCR at full dose $\left(1.5 \mathrm{mg} / \mathrm{m}^{2}\right)$ first, and completely omit the second dose (scheduled just five days later): no side effect was noted. The first reinduction protocol II started 22 days after completion of consolidation block therapy and the four weekly doses of VCR 


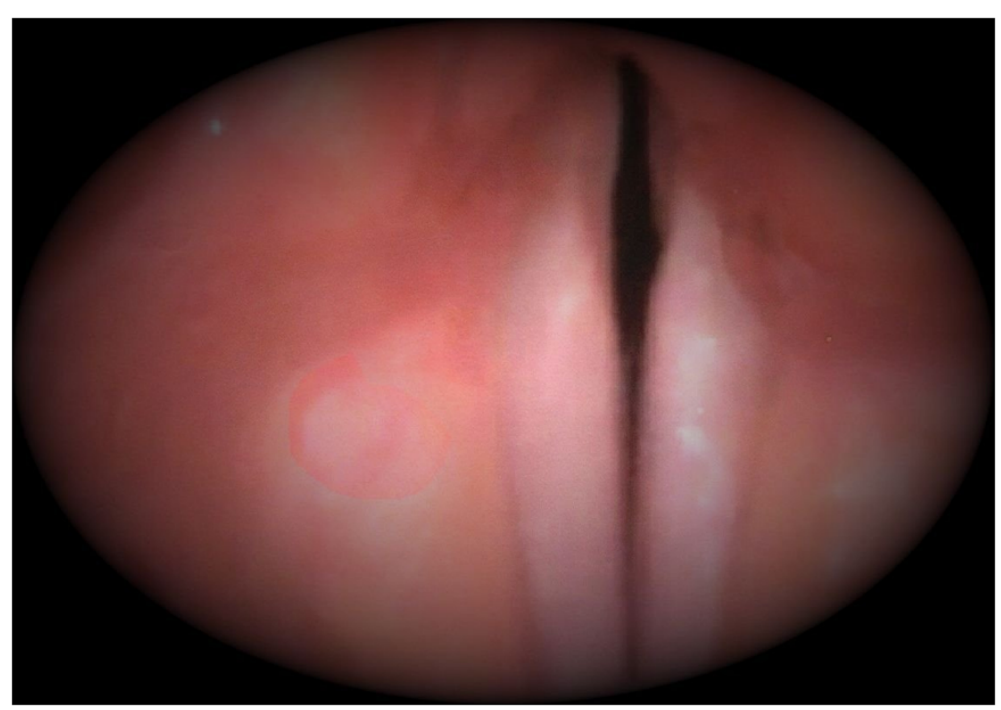

Figure 1 Vocal cord palsy: endoscopic view.

were uneventfully administered with a one-third reduction $\left(1 \mathrm{mg} / \mathrm{m}^{2}\right)$.

After four weeks of interim maintenance the second reinduction protocol II was scheduled and the first weekly dose of VCR was again administered at $1 \mathrm{mg} / \mathrm{m}^{2}$ without any problems; then our patient received glutamic acid $1.5 \mathrm{~g}$ daily orally in three divided doses and, one week later, a bolus injection of VCR was administered at full dose. Three days later she developed an intermittent hoarse voice lasting about 72 hours. Moreover, she manifested reduction of deep tendon reflexes, neuritic calf pain (treated with oral acetaminophen) and foot drop; the pain and foot drop resolved after about 24 hours. The following weekly VCR was omitted and glutamic acid was stopped after 10 days of overall treatment. The fourth and last dose of VCR was administered again at $1 \mathrm{mg} / \mathrm{m}^{2}$ and was well tolerated. She is now in complete remission and on maintenance therapy.

\section{Discussion}

VCP appears in an early report on the use of VCR, but it seems to be very rare; in a recent review the prevalence among children receiving VCR was $1.36 \%$ [1]. Analyzing the literature, we found 18 cases of children with VCRinduced VCP (Table 1) and our patient is the fifth girl reported [1-9].

Most cases are seen in younger children, with cases also reported in babies [5]; the median age is 2.7 years and 12 out of 18 patients were less than three years of age. The paralysis can be bilateral or, in about one-quarter of cases, unilateral, with the left vocal cord seemingly much more commonly affected (four cases versus one case of right
VCP). Swallowing problems are fairly common (about one-third of the patients) and, apparently only when the paralysis is bilateral, a period of mechanical ventilation may be required. Remarkably, assisted ventilation was necessary only in five out of 18 patients $[1,5,7,8]$. It is fairly certain that Down's syndrome patients are at higher risk of airway intervention (two out of two reported cases) $[1,7]$. The laryngeal dysfunction can be isolated or associated, as in about one-third of patients, with other manifestations of neurotoxicity, but never with other cranial neuropathies $[1-3,6,7,9]$. The problem resolves in a period of one to 10 months, usually with stridor resolving before the hoarseness. The median duration is six weeks.

The role of glutamic acid in decreasing VCR-induced neurotoxicity has been analyzed in some studies. Recently, a trial in a pediatric population [10] supported the efficacy of glutamic acid in preventing the neurological side effects of VCR via a mechanism that remains to be elucidated, but, to the best of our knowledge, it has never been used after first occurrence of neurotoxicity. In our patient glutamic acid, as rescue treatment, proved to be ineffective and when a full dose of VCR was given one week after a reduced dose, our patient showed not only a reappearance of stridor and hoarseness but also a transient peripheral neuropathy. On reviewing pediatric cases, reintroduction of VCR at half dose was associated with a recurrence of palsy in only one case out of six [8], and no respiratory failure developed. In contrast, besides our patient, there are only another two cases reported of VCR reintroduction at full dose [1,7], and in one of them there was a relapse [7]. 
Table 1 Literature review of pediatric patients with vincristine induced vocal cord palsy

\begin{tabular}{|c|c|c|c|c|c|c|c|c|}
\hline Authors & Sex/age & Diagnosis & $\begin{array}{l}\text { Duration, } \\
\text { weeks }\end{array}$ & $\begin{array}{l}\text { Vocal cord } \\
\text { palsy }\end{array}$ & $\begin{array}{l}\text { Airway } \\
\text { intervention }\end{array}$ & $\begin{array}{l}\text { Swallowing } \\
\text { dysfunction }\end{array}$ & $\begin{array}{l}\text { Associated } \\
\text { neuropathy }\end{array}$ & $\begin{array}{l}\text { Subsequent vincristine } \\
\text { administration }\end{array}$ \\
\hline \multirow[t]{2}{*}{ Tobias and Bozeman [2] } & M/5 years & ALL & 0.5 & L & No & No & No & Omitted \\
\hline & $\mathrm{F} / 2$ years & NHL-T & 2 & L & No & No & Yes & Half dose \\
\hline \multirow[t]{3}{*}{ Annino et al. [3] } & $\mathrm{M} / 1.5$ years & RMS & 6 & $\mathrm{BL}$ & No & Yes & No & Omitted \\
\hline & $\mathrm{M} / 1.3$ years & Ependymoma & 2 & BL & No & No & No & Omitted \\
\hline & $\mathrm{M} / 3$ years & ALL & 2 & L & No & No & Yes & Half dose \\
\hline Agarwall et al. [4] & $\mathrm{F} / 11$ years & LNH & NA & R & No & No & No & NA \\
\hline Anghelescu et al. [5] & $\mathrm{NA} / 0.4$ years & ALL & 1 & $B L$ & Yes & Yes & No & NA \\
\hline Graf et al. [6] & $\mathrm{M} / 15$ years & $A L L+C M T$ & 34.3 & $\mathrm{BL}$ & No & No & Yes & NA \\
\hline \multirow[t]{3}{*}{ Ahmad et al. [7] } & $\mathrm{M} / 3$ years & ALL + Down's & 38.5 & BL & Yes & Yes & No & Omitted \\
\hline & $\mathrm{M} / 1.8$ years & Ependymoma & 34.3 & $B L$ & No & No & No & Omitted \\
\hline & $\mathrm{M} / 2$ years & ALL & 27 & $B L$ & No & Yes & Yes & Omitted* \\
\hline \multirow[t]{4}{*}{ Kuruvilla et al. [1] } & F/1 year & ALL & 37 & $B L$ & Yes & Yes & No & Omitted \\
\hline & $\mathrm{M} / 4$ years & ALL + Down's & 20 & $B L$ & Yes & No & Yes & Half dose \\
\hline & $\mathrm{M} / 5$ years & ES & 7 & $\mathrm{BL}$ & No & No & No & No indication \\
\hline & M/3 years & RMS & 4 & L & No & Yes & & $\begin{array}{l}\text { Half dose, then increased to } \\
\text { regular regimen }\end{array}$ \\
\hline \multirow[t]{2}{*}{ Latiff et al. [8] } & $\mathrm{M} / 2$ years & ALL & 13 & $B L$ & No & No & No & Half dose $e^{* *}$ \\
\hline & $F / 3$ years & ALL & 40 & $\mathrm{BL}$ & Yes $^{* * *}$ & No & No & Half dose \\
\hline Naithani et al. [9] & $\mathrm{M} / 14$ years & ALL & 6 & $\mathrm{BL}$ & No & Yes & Yes & Omitted \\
\hline
\end{tabular}

*Vincristine definitely omitted after symptoms recurrence in consequence of drug reintroduction at full dose (drug initially given at $25 \%$ of recommended dose and gradually increased to full dose). **Vincristine definitely omitted after symptoms recurrence in consequence of drug reintroduction at half dose.

****ordectomy.

ALL = acute lymphoblastic leukemia; BL = bilateral; $C M T=$ Charcot Marie Tooth; Down's = Down's syndrome; ES = Ewing's sarcoma; $L=$ left; NA = not assessed; NHL-T = T cell non-Hodgkin's lymphoma; R = right; RMS = rhabdomyosarcoma. 


\section{Conclusions}

In our opinion the administration of weekly VCR at half to two-thirds dose should be the recommended initial approach after a case of drug-induced vocal cord palsy. We have not found evidence that administration of glutamic acid can prevent relapse of VCP.

\section{Consent}

Written informed consent was obtained from the parents of the patient for publication of this case report and any accompanying images. A copy of the written consent is available for review by the Editor-in-Chief of this journal.

\section{Competing interests}

The authors declare that they have no competing interests.

\section{Acknowledgments}

The authors wish to thank Professor Frank Adamo for the language support in revising the manuscript, and the Parents' Association "A.S.L.T.I.-Liberi di

Crescere" Onlus for financial support.

\section{Author details}

${ }^{1}$ Oncology Department, Pediatric Hematology and Oncology Unit, A.R.N.A.S. Ospedali Civico, Di Cristina e Benfratelli, Piazza N. Leotta 4, Palermo 90127, Italy. ${ }^{2}$ Clinic Department, Pharmaceutical Laboratory, A.R.N.A.S. Ospedali Civico, Di Cristina e Benfratelli, Piazza N. Leotta 4, Palermo 90127, Italy.

\section{Authors' contributions}

PF made substantial contributions to the structure of the manuscript, was involved in clinical management of our patient and drafted the manuscript. ST was involved in clinical management and helped draft the manuscript. SC and GB analyzed and interpreted patient data regarding disease. GO was involved in pharmaceutical management of the disease, and participated in drafting part of the manuscript. PD made substantial contributions to the structure of the manuscript, was involved in clinical management of our patient, and was a major contributor in writing the manuscript. All authors read and approved the final manuscript.

Received: 1 December 2011 Accepted: 14 May 2012

Published: 14 May 2012

\section{References}

1. Kuruvilla G, Perry S, Wilson B, El-Hakim H: The natural history of vincristine-induced laryngeal paralysis in children. Arch Otolaryngol Head Neck Surg 2009, 135:101-105.

2. Tobias JD, Bozeman PM: Vincristine-induced recurrent laryngeal nerve paralysis in children. Intensive Care Med 1991, 17:304-305.

3. Annino DJ, MacArthur CJ, Friedman EM: Vincristine induced recurrent laryngeal nerve paralysis. Laryngoscope 1992, 102: 1260-1262.

4. Agarwal P, Chavarkar M, Parelkar S, Oak SN: Vincristine induced right vocal cord palsy in a case of Non-Hodgkins lymphoma - a case report. J Indian Assoc Pediatr Surg 2002, 7:2002-2004.

5. Anghelescu DL, De Armendi AJ, Thompson JW, Sillos EM, Pui CH, Sandlund JT: Vincristine-induced vocal cord paralysis in an infant. Pediatr Anaesth 2002, 12:168-170.

6. Graf WD, Chance PF, Lensch MW, Eng L, Lipe HP, Bird TD Severe vincristine neuropathy in Charcot-Marie Tooth disease type 1A. Cancer 1996, 77:1356-1362.

7. Ahmad A, Williams D, Nicholson J: Vincristine-induced bilateral vocal cord paralysis in children. Pediatr Blood Cancer 2007, 48:248.

8. Latiff ZA, Kamal NA, Jahendran J, Alias H, Goh BS, Syed Zakaria SZ, Jamal R: Vincristine-induced vocal cord palsy: case report and review of the literature. J Pediatr Hematol Oncol 2010, 32(5):407-410.

9. Naithani R, Dolai TK, Kumar R: Bilateral vocal cord paralysis following treatment with vincristine. Indian Pediatr 2009, 46:68-69.
10. Mokhtar GM, Shaaban SY, Elbarbary NS, Fayed WA A trial to assess the efficacy of glutamic acid in prevention of vincristine-induced neurotoxicity in pediatric malignancies: a pilot study. J Pediatr Hematol Oncol 2010, 32:594-600.

doi:10.1186/1752-1947-6-128

Cite this article as: Farruggia et al:: Vocal cord palsy after vincristine treatment in a child and the inefficacy of glutamic acid in the prevention of relapse: a case report. Journal of Medical Case Reports 2012 6:128.

\section{Submit your next manuscript to BioMed Central and take full advantage of:}

- Convenient online submission

- Thorough peer review

- No space constraints or color figure charges

- Immediate publication on acceptance

- Inclusion in PubMed, CAS, Scopus and Google Scholar

- Research which is freely available for redistribution 